University of Nebraska - Lincoln

DigitalCommons@University of Nebraska - Lincoln

Roger Kirby Publications

Research Papers in Physics and Astronomy

2-15-1974

\title{
Phonon-induced second-order Raman scattering in LiF
}

T.P. Sharma

University of Nebraska-Lincoln

Roger D. Kirby

University of Nebraska-Lincoln, rkirby1@unl.edu

Sitaram Jaswal

University of Nebraska, sjaswal1@unl.edu

Follow this and additional works at: https://digitalcommons.unl.edu/physics_kirby

Part of the Physics Commons

Sharma, T.P.; Kirby, Roger D.; and Jaswal, Sitaram, "Phonon-induced second-order Raman scattering in LiF" (1974). Roger Kirby Publications. 29.

https://digitalcommons.unl.edu/physics_kirby/29

This Article is brought to you for free and open access by the Research Papers in Physics and Astronomy at DigitalCommons@University of Nebraska - Lincoln. It has been accepted for inclusion in Roger Kirby Publications by an authorized administrator of DigitalCommons@University of Nebraska - Lincoln. 


\title{
Phonon-induced second-order Raman scattering in LiF
}

\author{
T. P. Sharma, * R. D. Kirby, ${ }^{\dagger}$ and S. S. Jaswal $\ddagger$ \\ Behlen Laboratory of Physics, University of Nebraska, Lincoln, Nebraska 68508 \\ (Received 6 August 1973)
}

\begin{abstract}
We have studied experimentally and theoretically the second-order Raman spectra of LiF. Theoretical calculations based on Born and Bradburn's approach explain the observed spectra fairly well when all the eight-nearest-neighbor, only two of the fifteen-next-nearest-neighbor negative-negative, and none of the fifteen next-nearest-neighbor positive-positive polarizability coefficients are used as adjustable parameters.
\end{abstract}

We have made a detailed experimental and theoretical study of second-order Raman scattering in LiF. Experimentally, the Raman spectra of a single crystal of LiF, obtained from the Harshaw Chemical Co., were taken using a Coherent Radiation model-52 argon-ion laser and a Spex model1401 double monochromater. The Raman spectra were obtained using a standard $90^{\circ}$ scattering geometry with [110] oriented samples. The combinations of the incident and scattered light polarizations for the observed spectra are given in Table I. The three independent Raman spectra for cubic crystals are $A_{1 g}, E_{g}$, and $T_{2 g}$ in group-theoretic notation and the spectra reported here are $T_{28}$ $(T), \frac{1}{4} E_{g}(E)$, and $\frac{1}{3}\left(A_{1 g}+E_{g}\right)(A E)$ in the notation of Ref. 1. For all the spectra, the $488-\mathrm{nm}$ line of the argon laser was used, with a narrow -band interference filter to suppress fluorescence lines from the laser plasma tube. The spectra were also checked with the $514.5-\mathrm{nm}$ laser line to elimi nate any sample fluorescence. The smooth curves in Figs. 2-5 show the Stokes-shifted room-temperature experimental spectra for an instrumental resolution of $6 \mathrm{~cm}^{-1}$. Spectra were also taken at liquid-nitrogen temperature but are not included here because they are similar to the room-temperature spectra except for the sharpening of the over-all structure and the disappearance of the difference band peak at $85 \mathrm{~cm}^{-1}$. In all the plots the $T$ and $E$ spectra have been amplified 10 and 2 times, respectively. Our $E$ and $A E$ spectra are quite similar to those previously reported by Evans and Fitchens, ${ }^{2}$ except for a small bump at $420 \mathrm{~cm}^{-1}$ in the present $A E$ spectrum. The present $T_{2 g}$ spec-

TABLE I. Combinations of the incident and scattered light polarizations for the observed spectra.

\begin{tabular}{ccc}
\hline \hline \multicolumn{2}{c}{ Polarization of light } \\
Incident & Scattered & Spectra \\
\hline$[110]$ & {$[001]$} & $T_{2 g}$ \\
{$[110]$} & {$[\overline{1} 10]$} & $\frac{1}{4} E_{g}$ \\
{$[001]$} & {$[001]$} & $\frac{1}{3}\left(A_{1 \boldsymbol{g}}+E_{g}\right)$ \\
\hline \hline
\end{tabular}

trum has some structure whereas that reported by Evans and Fitchens is essentially featureless.

The theoretical analysis of the observed spectra is based on the theory due to Born and Bradburn ${ }^{3}$ in which the second-order expansion coefficients of the polarizability tensor are treated as adjustable parameters. The details of the theory are given in Ref. 1. The Raman-intensity expression is a weighted two-phonon density of states with the weight factor being a function of the phonon fre quencies and the corresponding eigenvectors, polarizability coefficients, and the temperature.

A deformation dipole model formulated here for the lattice dynamics of LiF is based on the roomtemperature neutron scattering phonon dispersion curves ${ }^{4}$ for $\mathrm{Li}^{7} \mathrm{~F}$ and the $85-\mathrm{cm}^{-1}$ difference band peak in the second-order Raman spectra. In this model we consider the deformations due to the nearest-neighbor short-range central forces only, with the deformation dipoles on the negative as well as the positive ions. The short-range forces consist of the central forces between the first and second neighbors and an angle bending force with the apex at the positive ion. ${ }^{5}$ The elastic constants $C_{11}$ and $C_{44}$ were varied slightly from the experimental data of Haussühl $\left(C_{11}=11.36 \times 10^{11} \mathrm{dyn} / \mathrm{cm}^{2}\right.$, $C_{44}=6.35 \times 10^{11} \mathrm{dyn} / \mathrm{cm}^{2}$ ) to improve the agreement between the theoretical and experimental lattice dynamics, with their final values being $11.86 \times 10^{11}$ and $6.65 \times 10^{11} \mathrm{dyn} / \mathrm{cm}^{2}$, respectively. Some of the input data are given in Table $\Pi$. The various parameters of the lattice-dynamical model are listed in Table III. As shown in Fig. 1 the agreement between the calculated phonon dispersion curves and the neutron scattering results for $\mathrm{Li}^{7} \mathrm{~F}$ is quite good.

For reference we list the calculated Ramanactive two-phonon combinations at the $\Gamma, X$, and $L$ points in the Brillouin zone in Table IV and compare the calculated temperature-weighted two-phonon density histogram with the experimental spectra in Fig. 2.

We follow Ref. 1 in computing the Raman spectra where the polarizability coefficients are treated as 
TABLE II. Input Data.

\begin{tabular}{ll}
\hline Elastic constant $^{2}$ & $C_{12}=4.76 \times 10^{11} \mathrm{dyn} / \mathrm{cm}^{2}$ \\
Nearest-neighbor distance $^{\mathrm{b}}$ & $r_{0}=2.019 \AA$ \\
Szigeti charge $^{\mathrm{c}}$ & $e^{*}=0.80 e$ \\
Restrahlen frequency $^{\mathrm{d}}$ & $\omega_{\mathrm{TO}}=5.748 \times 10^{13} \mathrm{rad} / \mathrm{sec}$ \\
Polarizabilities $^{\mathrm{e}}$ & $\begin{array}{l}\alpha_{+}=0.029 \times 10^{-24} \mathrm{~cm}^{3} \\
\alpha_{-}=0.876 \times 10^{-24} \mathrm{~cm}^{3}\end{array}$ \\
\hline \hline
\end{tabular}

${ }^{2}$ Reference 6 .

${ }^{b}$ R. W. G. Wyckoff, Crystal Structures (Wiley, New York, 1964), Vol. 1.

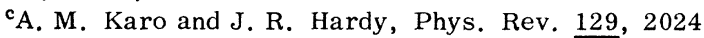
(1963).

${ }^{\mathrm{d}}$ Reference 4 .

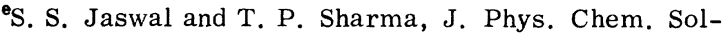
ids 34,509 (1973).

adjustable parameters. Because of their shortrange nature, these parameters are assumed to be nonzero between the first and second neighbors only. The calculations were started with all the first-neighbor parameters and the second-neighbor parameters were introduced as required to improve the agreement between theory and experiment. A minimization program was used to get an initial estimate of the parameters. The parameters were further refined by studying the effect of each one of them on the calculated spectra. We were able to get reasonable agreement between theory and experiment for the $E$ and $T$ spectra with the nearest-neighbor (NN) polarizability parameters, whereas two negative-negative next-nearest-neighbor (NNN) parameters were required for the $A E$ spectrum. The computed results are compared with the experimental spectra in Figs. 3-5, where the histograms I and II are the theoretical results based on NN and NNN polarizabilityparameter approximations, respectively, and the

TABLE III. Final parameters of the deformation dipole model.

\begin{tabular}{|c|c|c|}
\hline \multicolumn{3}{|c|}{ Monopole charge $=0.90 e$} \\
\hline \multicolumn{2}{|c|}{$\begin{array}{l}\text { Short-range parameters in } \\
\text { Kellermann's notations }\end{array}$} & $\begin{array}{l}\text { Deformation parameters } \\
\text { in Hardy's notation }\end{array}$ \\
\hline First neighbor & $\left\{\begin{array}{l}A=6.806 \\
B=-1.209\end{array}\right.$ & $\begin{array}{l}\gamma_{+}=-0.6613 \times 10^{-12} \\
\gamma_{+}^{\prime}=0.3723 \times 10^{-11}\end{array}$ \\
\hline Second neighbor & $\left\{\begin{array}{l}A_{++}=0.06236 \\
A_{--}=0.5612 \\
B_{++}=0.01325 \\
B_{--}=0.1193\end{array}\right.$ & $\begin{array}{l}\gamma_{-}=0.5952 \times 10^{-11} \\
\gamma_{-}^{\prime}=-0.3350 \times 10^{-10}\end{array}$ \\
\hline $\begin{array}{l}\text { Angle-bending } \\
\text { force constants }\end{array}$ & $\left\{\begin{array}{l}C_{+}=0.2726 \\
C_{-}=0.0\end{array}\right.$ & \\
\hline
\end{tabular}

${ }^{2}$ E. W. Kellermann, Philos. Trans. R. Soc. Lond. 238, 513 (1940).

bJ. R. Hardy, Philos. Mag. ㄱ, 315 (1962).

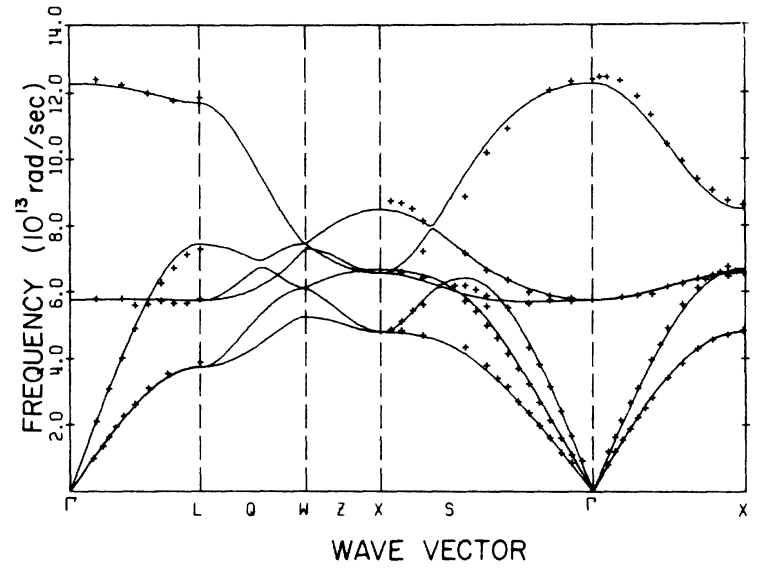

FIG. 1. Room-temperature phonon dispersion curves of $\mathrm{Li}^{7} \mathrm{~F}$ in the symmetry directions: Smooth curves are the calculated results based on a deformation dipole model and crosses are the neutron scattering results from Ref. 4.

smooth curves are the experimental spectra. The final values of the parameters are listed in Table V.

TABLE IV. Raman-active phonon combinations at the symmetry points.

\begin{tabular}{|c|c|c|c|c|c|}
\hline $\begin{array}{l}\text { Symmetry } \\
\text { point }\end{array}$ & Combinations & $\begin{array}{l}\text { Calculated } \\
\text { frequencies } \\
\left(\mathrm{cm}^{-1}\right)\end{array}$ & $A_{1 \mathrm{~g}}^{\mathrm{St}}$ & $E_{g}$ & $T_{2 \xi}$ \\
\hline \multirow[t]{3}{*}{$\Gamma$} & $2 \mathrm{LO}$ & 1309 & $\mathrm{x}$ & $\mathrm{x}$ & $\mathrm{x}$ \\
\hline & $\mathrm{LO}+\mathrm{TO}$ & 961 & $\mathrm{x}$ & $\mathrm{x}$ & $\mathrm{x}$ \\
\hline & $\begin{array}{l}\mathrm{LO}-\mathrm{TO} \\
2 \mathrm{LO}\end{array}$ & $\begin{array}{l}348 \\
907\end{array}$ & $\begin{array}{l}\mathrm{x} \\
\mathrm{x}\end{array}$ & $\begin{array}{l}\mathrm{x} \\
\mathrm{x}\end{array}$ & $\mathrm{x}$ \\
\hline \multirow{15}{*}{$X$} & $\mathrm{LO}+\mathrm{TO}$ & 804 & & & $\mathrm{x}$ \\
\hline & LO - TO & 104 & & & $\mathrm{x}$ \\
\hline & $\mathrm{LO}+\mathrm{LA}$ & 808 & $\mathrm{x}$ & $\mathrm{x}$ & \\
\hline & LO - LA & 99 & $\mathrm{x}$ & $\mathrm{x}$ & \\
\hline & $\mathrm{LO}+\mathrm{TA}$ & 708 & & & $\mathrm{x}$ \\
\hline & $\mathrm{LO}-\mathrm{TA}$ & 199 & & & $\mathrm{x}$ \\
\hline & $2 \mathrm{TO}$ & 800 & $\mathrm{x}$ & $\mathrm{x}$ & $\mathrm{x}$ \\
\hline & $\mathrm{TO}+\mathrm{LA}$ & 704 & & & $\mathrm{x}$ \\
\hline & LA - TO & 4.6 & & & $\mathrm{x}$ \\
\hline & $\mathrm{TO}+\mathrm{TA}$ & 604 & $\mathrm{x}$ & $\mathrm{x}$ & $\mathrm{x}$ \\
\hline & $\mathrm{TO}-\mathrm{TA}$ & 95 & $\mathrm{x}$ & $\mathrm{x}$ & $\mathrm{x}$ \\
\hline & $2 \mathrm{LA}$ & 709 & $\mathrm{x}$ & $\mathrm{x}$ & \\
\hline & $\mathrm{LA}+\mathrm{TA}$ & 609 & & & $\mathrm{x}$ \\
\hline & $\mathrm{LA}-\mathrm{TA}$ & 100 & & & $\mathrm{x}$ \\
\hline & $2 \mathrm{TA}$ & 509 & $\mathrm{x}$ & $\mathrm{x}$ & $\mathrm{x}$ \\
\hline \multirow[t]{8}{*}{$L$} & $2 \mathrm{LO}$ & 1250 & $\mathrm{x}$ & & $\mathrm{x}$ \\
\hline & $\mathrm{LO}+\mathrm{TO}$ & 1020 & & $\mathrm{x}$ & $\mathrm{x}$ \\
\hline & $\mathrm{LO}-\mathrm{TO}$ & 230 & & $\mathrm{x}$ & $\mathrm{x}$ \\
\hline & $2 \mathrm{TO}$ & 790 & $\mathrm{x}$ & $\mathrm{x}$ & $\mathrm{x}$ \\
\hline & $2 \mathrm{LA}$ & 611 & $\mathrm{x}$ & & $\mathrm{x}$ \\
\hline & $\mathrm{LA}+\mathrm{TA}$ & 504 & & $\mathrm{x}$ & $\mathrm{x}$ \\
\hline & $\mathrm{LA}-\mathrm{TA}$ & 107 & & $\mathrm{x}$ & $\mathrm{x}$ \\
\hline & $2 \mathrm{TA}$ & 398 & $\mathrm{x}$ & $\mathrm{x}$ & $\mathrm{x}$ \\
\hline
\end{tabular}




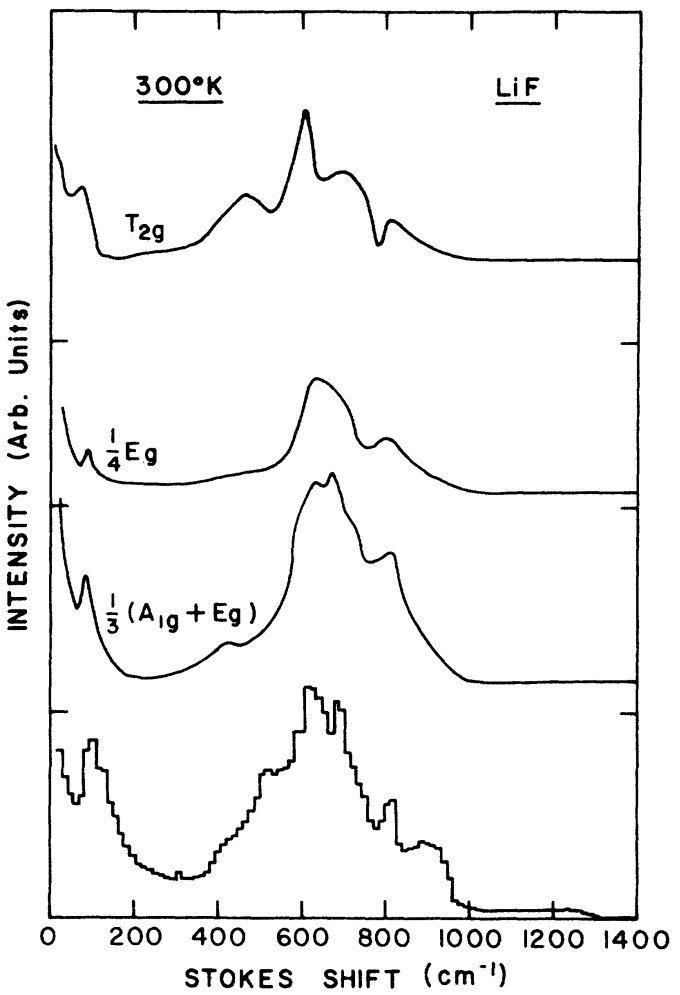

FIG. 2. Room-temperature Raman spectra (smooth lines) and the temperature-weighted two-phonon densityof-states histogram. The scales for the $T$ and $E$ spectra have been amplified 10 times and 2 times, respectively.

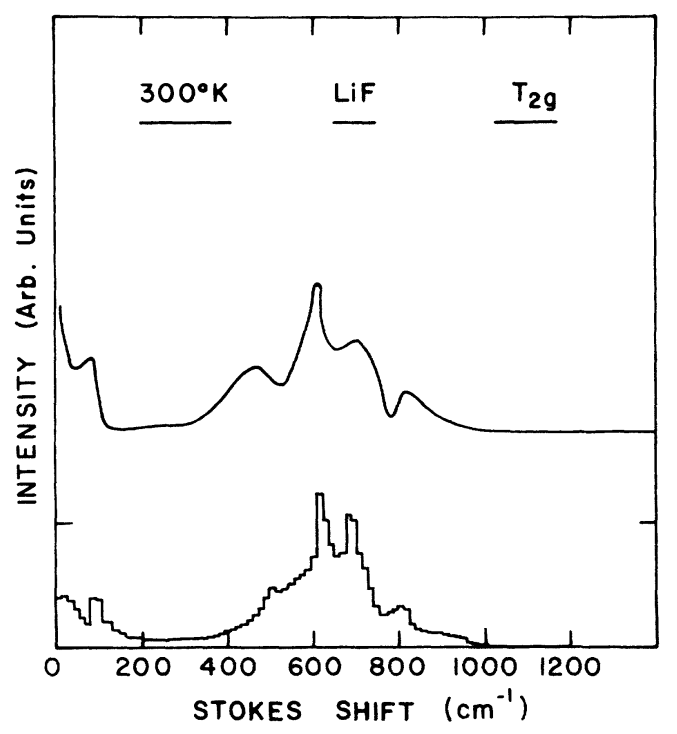

FIG. 3. $T_{2 g}$ spectra: Smooth line is the experimental room-temperature spectrum and histogram $I$ is the calculated spectrum in the nearest-neighbor polarizability approximation.

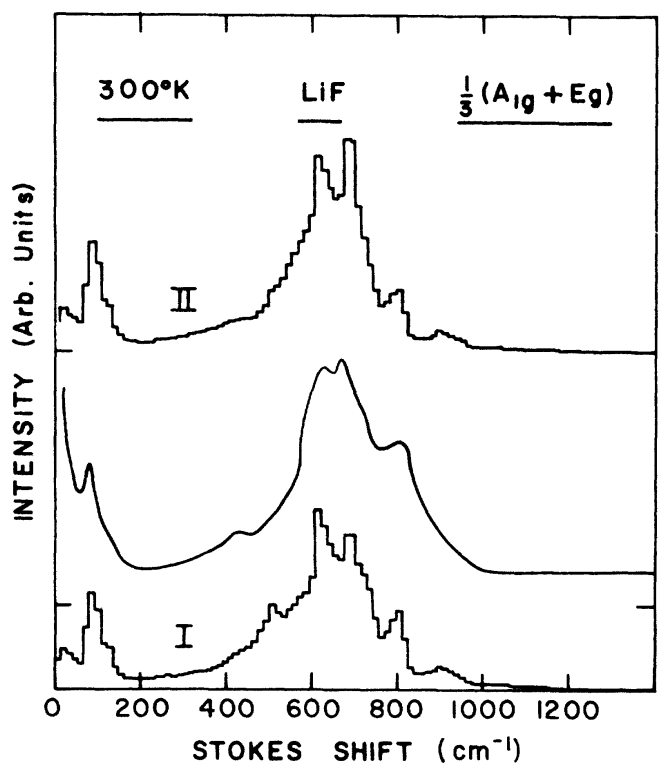

FIG. 4. $\frac{1}{3}\left(A_{18}+E_{g}\right)$ Spectra: Solid line is the experimental room-temperature spectrum and histograms I and II are the calculated spectra in the nearest- and nextnearest-neighbor polarizability approximations, respectively.

A brief discussion of the results is as follows:

$T_{2 g}$ spectra. The calculated and observed $T_{2 g}$ spectra are given in Fig. 3. The calculated histogram is based on the NN polarizability parameters listed in Table $\mathrm{V}$. The NN parameters did not improve the calculated results any further. The over-all agreement between the calculated and experimental results is quite reasonable.

$\frac{1}{3}\left(A_{1 g}+E_{g}\right)$ spectra. Figure 4 shows the observed and calculated $A E$ spectra. The calculated results based on the NN parameters only (histogram I) do not agree with the experimental results in the regions of $400-500$ and $900 \mathrm{~cm}^{-1}$. The introduction of the negative-negative NNN parameters improves

TABLE V. Polarizability coefficients $P_{\alpha \beta \gamma b}\left(k_{k K^{\prime}}^{l}\right)$ for the first- and second-ne ighbor ions denoted by their subscripts $\alpha \beta \gamma \delta$.

\begin{tabular}{|c|c|c|}
\hline & $\begin{array}{r}\alpha \beta \gamma \delta\left(\begin{array}{l}l \\
k K^{\prime}\end{array}\right)^{2} \\
T_{2 \xi}\end{array}$ & $A_{1 g^{\prime}} E_{g}$ \\
\hline $\begin{array}{c}\text { [100] nearest-neighbor } \\
\text { ions }\end{array}$ & $\begin{array}{l}2323=2.3 \\
3131=-2.6 \\
1212=1.5\end{array}$ & $\begin{array}{l}1111=-14.5 \\
2222=6.4 \\
2233=0.9 \\
1122=6.3 \\
2211=-3.5\end{array}$ \\
\hline $\begin{array}{c}\text { [110] next-nearest- } \\
\text { neighbor negative } \\
\text { ions }\end{array}$ & & $\begin{array}{l}1111=-1.5 \\
1122=-1.5\end{array}$ \\
\hline
\end{tabular}

${ }^{2} P_{\alpha \beta \gamma 6}\left({ }_{k k^{\prime}}^{l}\right)$ is symmetric in the first two subscripts. 


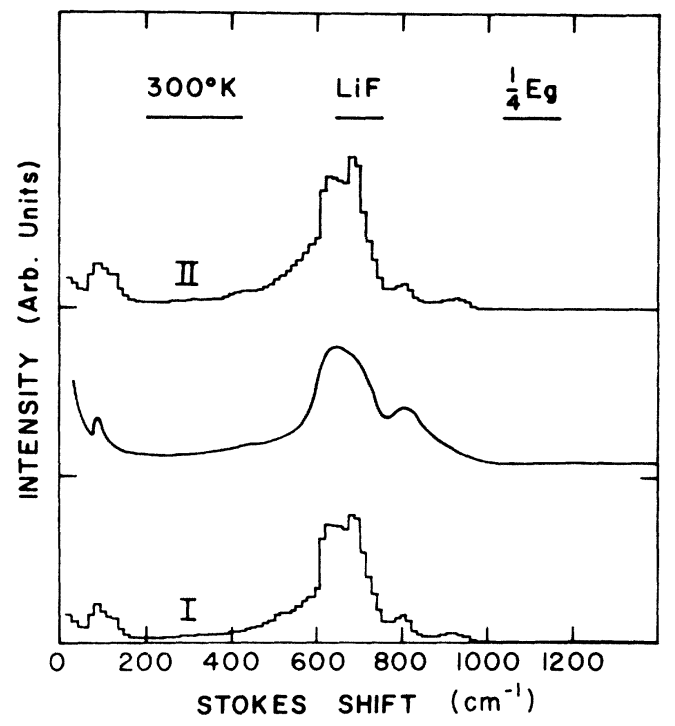

FIG. 5. $\frac{1}{4} E_{\boldsymbol{g}}$ Spectra: Solid line is the experimental room-temperature spectrum and histograms I and II are the calculated spectra in the nearest- and next-nearestneighbor polarizability approximations, respectively.

the agreement in the region of $400-500 \mathrm{~cm}^{-1}$ but the disagreement at $900 \mathrm{~cm}^{-1}$ remains (histogram II). Since the $\mathrm{F}^{-}$ion is much bigger than the $\mathrm{Li}^{+}$ion, the need for some second-neighbor parameters for negative ions is quite reasonable. Once again the over-all agreement between the theory and experiment is good. The NN and NNN polarizability parameters are listed in Table $\mathrm{V}$.

$\frac{1}{4} E_{g}$ spectra: Finally, the $E$ spectra are plotted in Fig. 5. Since the polarizability parameters for $E_{g}$ and $A_{1 g}$ spectra are the same, the calculated $E$ spectra are based on the parameters fitted to the $A E$ spectra. As can be seen in Fig. 5 , the $E_{g}$ spectrum is essentially insensitive to the NNN parameters. Except for a small bump in the calculated spectrum at $900 \mathrm{~cm}^{-1}$ the calculated and observed spectra are in very good agreement.

In conclusion we have studied experimentally and theoretically the room-temperature second-order Raman spectra $\left[T_{2 g}, \frac{1}{3}\left(A_{1 g}+E_{g}\right)\right.$, and $\left.\frac{1}{4} E_{g}\right]$ of LiF. The theoretical calculations based on Born and Bradburn's approach explain all the observed spectra quite well with all the eight nearest-neighbor polarizability coefficients and only two (negativenegative) out of thirty next-nearest-neighbor coefficients. The fitted values of these parameters should be helpful in understanding their theoretical basis.

We wish to thank Professor John Weymouth for supplying the single crystal used in this investigation. We are thankful to Dr. Walter H. Bruning, Computer Network Director, University of Nebras$\mathrm{ka}$, and the staff of the Lincoln Computing Facility for the use of the computer in the present calculations.
*Supported in part by the University of Nebraska Research Council.

†Supported in part by National Science Foundation under Departmental Development Grant No. GU3163,

†Supported in part by a Senior Faculty Summer Fellowship from the University of Nebraska Research Council in 1973.

${ }^{1}$ S. S. Jaswal, G. Wolfram, and T. P. Sharma, J. Phys. Chem. Solids (to be published).

${ }^{2}$ A. R. Evans and D. B. Fitchens, Solid State Commun.
8, 537 (1970).

${ }^{3} \vec{M}$. Born and M. Bradburn, Proc. R. Soc. Lond. A 241 , 105 (1948).

${ }^{4}$ G. Dolling, H. G. Smith, R. M. Nicklow, P. R.

Vijayaraghavan, and M. K. Wilkinson, Phys. Rev. 168, 970 (1968).

${ }^{5}$ S. S. Jaswal and J. R. Hardy, Phys. Rev. 171, 1090 (1968).

${ }^{6}$ S. Haussühl, Z. Phys. 159, 223 (1960). 